\title{
A study of causes, investigation and management of structural causes of abnormal uterine bleeding in reproductive age group
}

\author{
Vibhusha S. Rohidas*, Niranjan N. Chavan
}

Department of Obstetrics and Gynaecology, Lokmanya Tilak Municipal General Hospital and Medical College, Mumbai, Maharashtra, India

Received: 30 May 2020

Revised: 05 August 2020

Accepted: 03 September 2020

*Correspondence:

Dr. Vibhusha S. Rohidas,

E-mail: vibhusha_rs@yahoo.co.in

Copyright: () the author(s), publisher and licensee Medip Academy. This is an open-access article distributed under the terms of the Creative Commons Attribution Non-Commercial License, which permits unrestricted non-commercial use, distribution, and reproduction in any medium, provided the original work is properly cited.

\section{ABSTRACT}

Background: Abnormal uterine bleeding (AUB) is debilitating condition affecting 14-25\% of women of reproductive age. It has significant impact on women's personal, social, physical and quality of life. Present study is planned to study causes, investigation along with management of structural causes of abnormal uterine bleeding in reproductive age group.

Methods: Consecutive type of non-probability sampling was used for selection of study subjects. A total of 100 gynaecology OPD women diagnosed with menorrhagia of 15-45 years age group were enrolled in study.

Results: Mean age of the study subjects was between 26-35 years (47\%). 67\% were from low socio-economic class while 33\% were from middle class. Maximum number of women (66\%) had symptoms for less than 6 months. $47 \%$ presented with Menorrhagia. $89 \%$ were Multiparous, and $11 \%$ were Nulliparous. Most common structural causes of AUB was leiomyoma (41\%) followed by polyps (23\%), adenomyosis (17\%), endometrial hyperplasia (15\%) and endometrial carcinoma (4\%). Prevalence of anemia was $73 \%$ in present study. Maximum leiomyoma were treated medically while higher percentage of polyps and hyperplasia was treated surgically. Most commonly performed surgery was polypectomy (20\%) followed by dilatation and curettage (17\%) and myomectomy (15\%). Total abdominal hysterectomy was done in $8 \%$ cases while radical hysterectomy was done in $2 \%$ cases.

Conclusions: Benign lesions of endometrium account for majority of cases presenting with AUB in reproductive age group. Other premalignant and malignant causes should also be considered. High prevalence of anemia was observed in these cases. A comparative clinicopathological study will help in arriving at the cause and correct diagnosis. Histopathological examination is one of the major tools in evaluation of abnormal uterine bleeding and helps us in proper management and treatment of cases.

Keywords: Abnormal uterine bleeding, Anaemia, Endometrial hyperplasia, Leiomyoma, Menorrhagia, Polyps, Reproductive age group

\section{INTRODUCTION}

Abnormal uterine bleeding (AUB) is a significant debilitating clinical condition and affects $14-25 \%$ of women of reproductive age and up to $50 \%$ of perimenopausal women. ${ }^{1}$ It may have a significant impact on women's personal, social, physical and quality of life with significant financial burden to the country's economy. ${ }^{2}$ Acute AUB is defined as bleeding in a non- pregnant woman of reproductive age of sufficient quantity to require immediate intervention to prevent further loss. ${ }^{3,4}$ Chronic AUB is defined as bleeding from the uterine corpus that is abnormal in duration, volume, and/or frequency and has been present for most of the previous 6 months. ${ }^{3}$

Historical literature of AUB reveals no universally accepted method for classifying AUB, which hampered 
the investigation and categorization of possible etiologies of AUB. ${ }^{5}$ The classic terminology that describes AUB include terms that are not related to the underlying etiology (e.g., menorrhagia, polymenorrhea etc.). In order to standardize definitions, nomenclature and the possible underlying etiologies of AUB, it was redefined by International Federation of Obstetrics and Gynecology (FIGO) in 2009 by the FIGO Menstrual Disorders Group (FMDG). ${ }^{3,4}$ This would simplify the investigation and comparison among homogenous populations and aid in research and evidence-based approach to AUB. The FIGO categorized AUB based on structured medical history, laboratory tests, ultrasound and or hysteroscopy based techniques. ${ }^{3}$ The classification is based on the acronym "PALM- COEIN", which stands for polyp, adenomyosis, leiomyoma, malignancy (and hyperplasia) and comprises structural pathologies assessed visually. ${ }^{3}$ The COEIN group stands for coagulopathy, ovulatory disorders, endometrial, iatrogenic, not otherwise classified and relates to non-structural etiologies that cannot be assessed by imaging or histopathology. ${ }^{3}$

Menstrual history and physical examination are the mainstay of evaluation of cases. After excluding pregnancy, the initial evolution includes a detailed history of bleeding and medical history focusing on risk factors for endometrial cancer, coagulopathies, medications in use, concomitant diseases, as well a complete physical examination focusing on signs of polycystic ovarian syndrome, insulin resistance, thyroid diseases, petechiae, bruises, vagina or cervix lesions, and uterine size. To further the investigation, blood counts, ferritin dosage and pelvic ultrasonography may be performed. ${ }^{6}$

In women with low risk for endometrial cancer and normal ultrasonography, excluding structural causes such as polyps, fibroids, endometrial thickening or other malignancies (classified in the PALM-COEIN system), the treatment can be pharmacological, through the use of drugs, or surgical. Structural lesions classified in the PALM-COEIN system have specific treatments according to the diagnosis. ${ }^{7}$

The goal of the treatment is the reduction of the menstrual flow, thereby reducing morbidity and improving quality of life. Treatment by drug or pharmacological therapy is considered the first line whenever possible. The effectiveness and adherence to this alternative is strongly linked to the medical care and excellency of the doctor-patient relationship. The provision of information about therapeutic resources, their mechanism of action, their benefits, risks, information on the expected outcomes, and guidance on the long-term use may be crucial for treatment continuity. ${ }^{7}$

The present hospital based observational study was planned to analyze the etiology, required investigations, management strategies and final outcome among cases with structural causes of abnormal uterine bleeding in reproductive age group.

\section{METHODS}

A prospective observational study (September 2017 to August 2019) was conducted at Department of Obstetrics and Gynaecology at tertiary care centre. A total of 100 cases of diagnosed with menorrhagia of 15-45 years age group were enrolled in the study.

\section{Inclusion criteria}

All gynaecology patients with menorrhagia of age group $15-45$ years are included in the study.

\section{Exclusion criteria}

Patients not willing to be included in the study; patients with any comorbidities like uncontrolled hypertension, hormonal imbalance; active internal bleeding or any high-risk factors causing potential risk of bleeding; and patients with iatrogenic causes, endometrial and ovulatory disorder.

\section{Study methodology}

For all patients demographic details and clinical history was taken. Detailed history included: detailed menstrual history was taken as regards onset, course, duration, amount of bleeding, medical history (DM, HTN, thyroid disorders), surgical history were recorded. Detail general, systemic and local examination to record the size of the uterus, its mobility and the presence of any cervical or adnexal masses was also carried out. Along with this complete blood count, coagulation profile and serum electrolytes were done for all patients. Ultrasonography was done in all cases while hysteroscopy and D and C was done where indicated. Pathological lesions if any were removed and sent for HPE. At the end of the procedure, the hysteroscope was slowly withdrawn through the cervical canal. After hysteroscopy, curettage was performed in four quadrant, representative endometrial sample were preserved in formalin solution and sent for histopathological examination.

All the collected data was entered in Microsoft Excel Sheet 2010. The data was then transferred and analyzed using SPSS ver. 21.

\section{RESULTS}

In present study, mean age of the study subjects was 33.21 years with almost half of the cases were between 26-35 years $(47 \%)$ (Table 1$)$.

Out of the total 100 cases, $67 \%$ were from low socioeconomic class while $33 \%$ were from middle class (Figure 1). 
Table 1: Distribution of cases as per age group.

\begin{tabular}{|lll|}
\hline Age group (years) & Number of cases $(\mathbf{N})$ & Percentage \\
\hline$\leq \mathbf{2 0}$ & 7 & 7.0 \\
\hline $\mathbf{2 1 - 2 5}$ & 23 & 23.0 \\
\hline $\mathbf{2 6 - 3 0}$ & 22 & 22.0 \\
\hline $\mathbf{3 1 - 3 5}$ & 25 & 25.0 \\
\hline $\mathbf{3 6 - 4 0}$ & 20 & 20.0 \\
\hline $\mathbf{4 1 - 4 5}$ & 3 & 3.0 \\
\hline Total & 100 & 100.0 \\
\hline
\end{tabular}

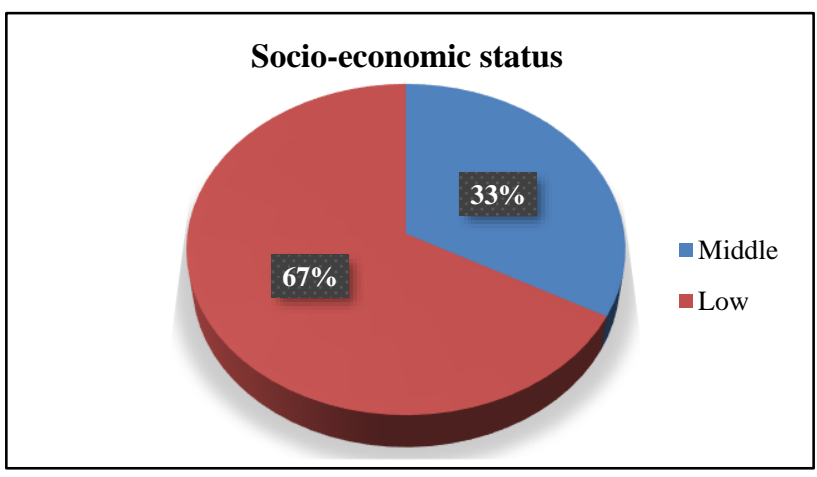

Figure 1: Distribution of cases as per socioeconomic status.

Of the 100 patients, maximum number of women $(66 \%)$ had symptoms for less than 6 months, 30 patients $(30 \%)$ had symptoms for 6 months to 1 year and 4 patients (4\%) had symptoms for more than 1 year (Figure 2).

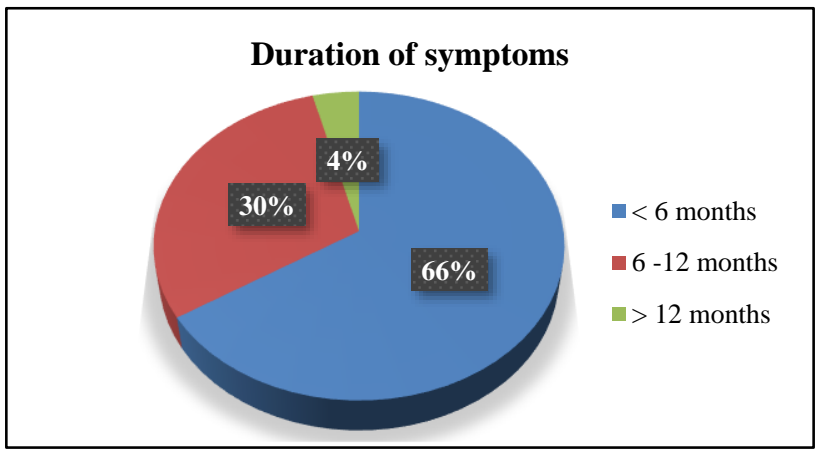

Figure 2: Distribution of cases as per duration of symptoms.

Table 2: Distribution of cases as per presenting symptoms.

\begin{tabular}{|lll|}
\hline Symptoms & $\begin{array}{l}\text { Number of } \\
\text { cases }(\mathbf{N})\end{array}$ & Percentage \\
\hline Menorrhagia & 47 & 47.0 \\
\hline Metrorrhagia & 24 & 24.0 \\
\hline Polymenorrhoea & 10 & 10.0 \\
\hline Polymenorrhagia & 18 & 18.0 \\
\hline Continuous bleeding & 1 & 1.0 \\
\hline Total & 100 & 100.0 \\
\hline
\end{tabular}

Out of total 100 patients, $47 \%$ presented with Menorrhagia. The next common presentation was metrorrhagia (24\%) followed by polymenorrhagia (18\%) and polymenorrhoea (10\%) (Table 2$)$.

Table 3: Distribution of cases as per obstetric history.

\begin{tabular}{|lll|}
\hline Obstetric history & Number of cases $(\mathbf{N})$ & Percentage \\
\hline Nulli-para & 11 & 11.0 \\
\hline Multi-para & 89 & 89.0 \\
\hline Total & 100 & 100.0 \\
\hline
\end{tabular}

Of the 100 patients, 89 cases (89\%) were multiparous, and 11 cases $(11 \%)$ were nulliparous.

Table 4: Distribution of cases as per etiology.

\begin{tabular}{|lll|}
\hline Etiology & Number of cases $(\mathbf{N})$ & Percentage \\
\hline Polyp & 23 & 23.0 \\
\hline Adenomyosis & 17 & 17.0 \\
\hline Leiomyoma & 41 & 41.0 \\
\hline Hyperplasia & 17 & 17.0 \\
\hline $\begin{array}{l}\text { Endometrial } \\
\text { carcinoma }\end{array}$ & 2 & 2.0 \\
\hline Total & 100 & 100.0 \\
\hline
\end{tabular}

The most common structural causes of abnormal uterine bleeding was leiomyoma $(41 \%)$ followed by polyps (23\%), adenomyosis (17\%), endometrial hyperplasia $(17 \%)$ and endometrial carcinoma $(2 \%)$.

Table 5: Distribution of cases as per prevalence of anaemia.

\begin{tabular}{|lll|}
\hline Anaemia & Number of cases $(\mathbf{N})$ & Percentage \\
\hline Yes & 73 & 73.0 \\
\hline No & 27 & 27.0 \\
\hline Total & 100 & 100.0 \\
\hline
\end{tabular}

Prevalence of anaemia was $73 \%$ in present study.

Table 6: Prevalence of anaemia as per respective etiologies.

\begin{tabular}{|c|c|c|c|}
\hline Etiology & $\begin{array}{l}\text { Number of } \\
\text { cases }(\mathbf{N})\end{array}$ & Anaemia & Percentage \\
\hline Polyp & 23 & 13 & 56.5 \\
\hline Adenomyosis & 17 & 12 & 70.6 \\
\hline Leiomyoma & 41 & 31 & 75.6 \\
\hline Hyperplasia & 17 & 15 & 88.2 \\
\hline $\begin{array}{l}\text { Endometrial } \\
\text { carcinoma }\end{array}$ & 2 & 2 & 100.0 \\
\hline Total & 100 & 73 & 73.0 \\
\hline
\end{tabular}

Highest prevalence of anaemia was seen in hyperplasia $(88.2 \%)$ and endometrial carcinoma cases (100\%). 
The type of management (medical/surgical) employed in various etiologies is given in the following figure.

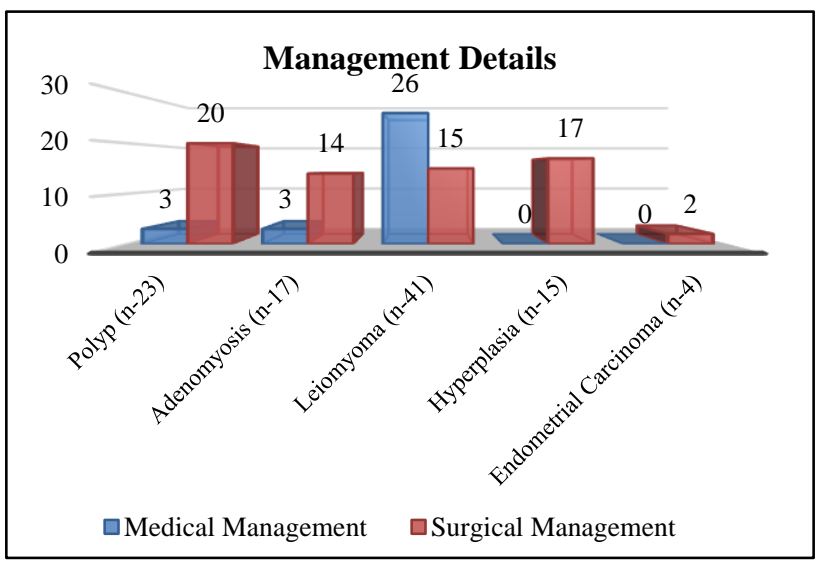

Figure 3: Management details of various etiologies.

Most commonly performed surgery was polypectomy (20\%) followed by dilatation and curettage (17\%) and myomectomy (15\%). Total abdominal hysterectomy was done in $8 \%$ cases while radical hysterectomy was done in $2 \%$ cases.

Table 7: Distribution of cases as per type of surgical management

\begin{tabular}{|lll|}
\hline Surgical management & $\begin{array}{l}\text { Number of } \\
\text { cases }(\mathbf{N})\end{array}$ & Percentage \\
\hline Polypectomy & 20 & 20.0 \\
\hline Myomectomy & 15 & 15.0 \\
\hline D and C & 17 & 17.0 \\
\hline TAH & 7 & 7.0 \\
\hline TAH and BSO & 1 & 1.0 \\
\hline Radical hysterectomy & 2 & 2.0 \\
\hline
\end{tabular}

\section{DISCUSSION}

A hospital based observational study was conducted to analyse the causes, investigation along with management of structural causes of abnormal uterine bleeding in reproductive age group. A total of 100 gynaecology OPD women diagnosed with menorrhagia of 15-45 years age group were enrolled in the study. For all patients demographic details and clinical history was taken. History including detailed menstrual history (as regards onset, course, duration, amount of bleeding), medical history (DM, HTN, thyroid disorders), surgical history were recorded. Detail general, systemic and local examination to record the size of the uterus, its mobility and the presence of any cervical or adnexal masses was also carried out. Along with this complete blood count, coagulation profile and serum electrolytes were done for all patients. Ultrasonography was done in all cases while hysteroscopy and D and C was done where indicated.

In present study, mean age of the study subjects was 33.21 years with almost half of the cases were between
26-35 years (47\%). Venugopalan et al studied the diagnosis and management of AUB in reproductive age females. ${ }^{8}$ Mean age of the study group was 37.8 years with over half of the cases were between 31-40 years $(52 \%)$. Similar distribution was seen in the studies by Sudha et al and Sun et al. ${ }^{9,10}$

Out of total 100 patients, $47 \%$ presented with Menorrhagia. The next common presentation was metrorrhagia (24\%) followed by polymenorrhagia (18\%) and polymenorrhoea (10\%). Panda et al series had $60 \%$ cases of menorrhagia followed by polymenorrhagia and metrorrhagia. ${ }^{11}$ Goyal et al in their study also observed menorrhagia as the commonest presenting symptom in the study population (58\%) followed by metrorrhagia, menometrorrhagia and continuous bleeding $>21$ days. $^{12}$ In a study, Chhikara et al observed the most common symptoms as menorrhagia (40\%) followed by metrorrhagia $38 \%$, polymenorrhagia $(12 \%)$ and postmenopausal bleeding $(10 \%) .{ }^{13}$ Similar findings were also observed by Gita et al et al and Sunitha et al. ${ }^{14,15}$

The most common structural causes of abnormal uterine bleeding in present study was leiomyoma (41\%) followed by polyps $(23 \%)$, adenomyosis $(17 \%)$, endometrial hyperplasia (15\%) and endometrial carcinoma (4\%). Venugopalan et al in a similar study observed fibroid uterus as the most common cause in the study population followed by polypandadenomyosis. ${ }^{8}$ Mishra et al in their study also observed most common structural causes of abnormal uterine as leiomyoma $(41.1 \%) .{ }^{16}$ Betha et al in their study aimed to categorize women with abnormal uterine bleeding (AUB) according to PALM COEIN classification system. ${ }^{17}$ The PALM and COEIN groups accounted for $60.4 \%$ and $39.6 \%$ respectively. Leiomyoma was the most common cause of AUB $(30.4 \%)$ and Ovulatory disorders was the $2^{\text {nd }}$ most common cause of AUB (13.6\%). Sudha et al observed the distribution of cases according to PALM-COEIN as polyps- $4 \%$, adenomyosis- $6 \%$, leiomyoma- $70 \%$, malignancy- $6 \%$, ovulatory dysfunction- $2 \%$, endometrial- 6\%, and not yet classified- 6\%. ${ }^{9}$ Wamsteker et al found endometrial polyp in 19\%, endometrial hyperplasia in $12.2 \%$ and submucousmyoma in $7.8 \% .^{18}$ Trotsenburg et al observed myomas and polyps in $14 \%$ and deWit reported myomas in $21 \%$ and polyps in 14.4. ${ }^{19,20}$

It was known fact that the patients having abnormal bleeding reduces the Hemoglobin levels, which ultimately leads to anaemia. In present study, prevalence of anaemia was seen in $73 \%$ cases of abnormal uterine bleeding. Highest prevalence of anaemia was seen in hyperplasia $(86.7 \%)$ and endometrial carcinoma cases $(100 \%)$. Matteson et al in their study observed approximately half (49.2\%) of the AUB had a concurrent medical condition which could affect their treatment options and $14 \%$ had moderate to severe anaemia. ${ }^{21}$ Venugopalan et al in their study observed prevalence of anaemia as $20 \%$ in our study. ${ }^{8}$ The higher prevalence in 
present study can be attributed to present hospital being tertiary care hospital catering to high risk cases.

Most commonly performed surgery was polypectomy (n$20 ; 20 \%$ cases) followed by dilatation and curettage (n$17 ; 17 \%$ cases) and myomectomy ( $\mathrm{n}-15 ; 15 \%$ cases). Total abdominal hysterectomy was done in $8 \%$ cases while radical hysterectomy was done in $2 \%$ cases. LNGIUS alone was given in 3 cases of polyp. It was also combined with polypectomy in 5 out of 20 cases. GnRH agonists were given in 3 out of 17 cases of adenomyosis while in 1 case OC pills were required. In cases of leiomyoma, management was started with Tranexamic acid or LNG-IUS as the initial treatment in all cases. In 15 cases, myomectomy was done due to treatment failure. All cases of hyperplasia and carcinoma were managed surgically.

\section{CONCLUSION}

In our study histopathological evaluation of endometrial tissue was undertaken to ascertain the etiology of abnormal uterine bleeding (AUB) in reproductive age women. Leiomyoma was the most common observed histopathological pattern in patients presenting with AUB. Endometrial polyp was the next important cause of AUB followed by adenomyosis. Though benign lesions of endometrium account for majority of cases presenting with AUB, in reproductive age group other premalignant and malignant causes should also be considered.

High prevalence of anaemia was observed in cases of AUB with highest prevalence being seen in malignant and pre-malignant cases.

A comparative clinicopathological study will help in arriving at the cause and correct diagnosis. Histopathological examination is one of the major tools in evaluation of abnormal uterine bleeding and helps us in proper management and treatment of cases.

Funding: No funding sources

Conflict of interest: None declared

Ethical approval: The study was approved by the Institutional Ethics Committee

\section{REFERENCES}

1. Fraser IS, Langham S, Uhl-Hochgraeber K. Health related quality of life and economic burden of abnormal uterine bleeding. Expert Rev Obstet Gynecol. 2009;4:179-89.

2. NICE. Clinical Guideline 44; Heavy menstrual bleeding. 2007. National Institute for Health and Clinical Excellence (NICE); Available at: https://www.nice.org.uk/guidance/ng88/evidence/full -guideline-pdf-4782291810.

3. Munro MG, Critchley HO, Broder MS, Fraser IS, FIGO Working Group on Menstrual Disorders System. FIGO classification system (PALM-COEIN) for causes of abnormal uterine bleeding in nongravid women of reproductive age. Int $\mathbf{J}$ Gynecol Obstet. 2011;113(1):3-13.

4. Fraser IS, Critchley HO, Broder M, Munro MG. The FIGO recommendations on terminologies and definitions for normal and abnormal uterine bleeding. Semin Reprod Med. 2011;29(5):383-90.

5. Woolcock JG, Critchley HO, Munro MG, Broder MS, Fraser IS. Review of the confusion in current and historical terminology and definitions for disturbances of menstrual bleeding. Fertil Steril. 2008;90(6):2269-80.

6. Davidson BR, DiPiero CM, Govoni KD, Littleton SS, Neal JL. Abnormal uterine bleeding during the reproductive years. J Midwife Womens Health. 2012;57(3):248-54.

7. Saidi MH, Sadler RK, Theis VD, Akright BD, Farhart SA, Villanueva GR. Comparison of sonography, sonohysterography, and hysteroscopy for evaluation of abnormal uterine bleeding. J Ultrasound Med. 1997;16(9):587-91.

8. Venugopalan SK, Pandian NS, Pavani M, Rao TS, Rajini Y, Khadeer SK. abnormal uterine bleeding in reproductive women: Diagnosis, management and treatment. Asian J Pharm Clin Res. 2015;8:42-5.

9. Sudha R, Pallavi YR. Distribution of causes of abnormal uterine bleeding according to polyp adenomyosis leiomyoma malignancy and hyperplasia coagulopathy ovulatory dysfunction endometrial latrogenic not yet classified classification in a tertiary care center. Int J Scient Stud. 2017;4(10):159-62.

10. Sun Y, Wang Y, Mao L, Wen J, Bai W. Prevalence of abnormal uterine bleeding according to new International Federation of Gynecology and Obstetrics classification in Chinese women of reproductive age: A cross-sectional study. Medicine. 2018;97(31):e11457.

11. Panda A, Parulekar SV, Gupta A. diagnostic hysteroscopy in abnormal uterine bleeding and its histopathological correlation. J Obst Gynecol India 1999; 175:74-6

12. Goyal BK, Gaur I, Sharma S, Saha A, Das NK. Transvaginal sonography versus hysteroscopy in evaluation of abnormal uterine bleeding. Med $\mathbf{J}$ Armed Forces India. 2015;71(2):120-5.

13. Chhikara A, Bharti A. Role of hysteroscopy in the evaluation of abnormal uterine bleeding. Indian $\mathbf{J}$ Appl Res. 2016;6(6).

14. Geeta G, Sandhu SK, Lele A, Khare S. Hysteroscopy in evaluation of abnormal uterine bleeding. J Obstet Gynecol India. 2011;61(5):546-9.

15. Sunitha $\mathrm{CH}$. A clinical study of diagnostic hysteroscopy in abnormal uterine bleeding and its histopathological correlation. IOSR J Dent Med Sci. 2013;5(3):43-46.

16. Mishra D, Sultan S. FIGO's PALM-COEIN classification of abnormal uterine bleeding: a clinicohistopathological correlation in Indian Setting. J Obstet Gynecol India. 2017;67(2):119-25. 
17. Betha K, Malavatu L, Talasani S. Distribution of causes of abnormal uterine bleeding using new FIGO classification system-PALM COEIN: a rural tertiary hospital based study. Int J Reprod Contracept Obstet Gynecol. 2017;6(8):3523-7.

18. Wamsteker K. Hysteroscopy in the management of abnormal uterine bleeding in 199 patients. In: Siegler AM, Lindemann HJ, editors. Hysteroscopy: Principles and Practice. Philadelphia: JB Lippincott; 1984:128-131.

19. VanTrotsenburg M, Wieser F, Naegle F. Diagnostic hysteroscopy for the investigation of abnormal uterine bleeding in premenopausal patients. Contrib Gynecol Obstet 2000;20:21-6.

20. deWit AC, Vleugels MP, deKruif JH. Diagnostic hysteroscopy: A valuable diagnostic tool in the diagnosis of structural intra-cavital pathology and endometrial hyperplasia or carcinoma? Six years of experience with non clinical diagnostic hysteroscopy. Eur J Obstet Gynecol Reprod Biol. 2003;110:79-82.

21. Matteson KA, Raker CA, Pinto SB, Scott DM, Frishman GN. Women presenting to an emergency facility with abnormal uterine bleeding: patient characteristics and prevalence of anaemia. J Reprod Med. 2012;57:17.

Cite this article as: Rohidas VS, Chavan NN. A study of causes, investigation and management of structural causes of abnormal uterine bleeding in reproductive age group. Int J Reprod Contracept Obstet Gynecol 2020;9:4021-6. 